\title{
EFEITO DO pH DA ÁGUA DE EMBEBIÇ̃̃O E DO TRINCAMENTO DAS SEMENTES DE MARACUJAZEIRO AMARELO NA GERMINAÇÃO E DESENVOLVIMENTO INICIAL
}

\author{
Effect of water pH of soaking and of cracking of the seeds of the yellow passion fruit in the \\ germination and initial development
}

\author{
Américo Wagner Júnior ${ }^{1}$, Jacson Rondinelli da Silva Negreiros ${ }^{2}$, Rodrigo Sobreira Alexandre ${ }^{1}$, \\ Leonardo Duarte Pimentel ${ }^{3}$, Claudio Horst Bruckner ${ }^{4}$
}

\begin{abstract}
RESUMO
O maracujazeiro está entre as principais fruteiras cultivadas no País, sendo semeadura o método predominante na produção de mudas. Objetivou-se com este trabalho avaliar o efeito do $\mathrm{pH}$ da água de embebição e do trincamento das sementes nos processos de germinação e desenvolvimento inicial do maracujazeiro amarelo, cultivar IAC 277. O trabalho foi realizado no Departamento de Fitotecnia, da Universidade Federal de Viçosa (MG). Os tratamentos foram constituídos de sementes trincadas e não trincadas embebidas durante 24 horas em solução de água destilada com pHs 3,0; 4,0; 5,0; 6,0 e 7,0. Posteriormente, no interior da casa-devegetação, as sementes foram semeadas em caixas plásticas contendo areia fina lavada. Foi utilizado o delineamento experimental em blocos casualizados, num fatorial 5 x 2 (pH da solução x trincamento da semente), com quatro repetições, considerando como unidade experimental, um lote de 50 sementes. Após 28 dias da semeadura, foram analisadas: porcentagem de germinação e sobrevivência; índice de velocidade de emergência; comprimento total; altura e comprimento da raiz primária e, massa da matéria seca total das plântulas. Concluiu-se que, os valores de $\mathrm{pH}$ das soluções de embebição foram favoráveis com os pHs de 3,81 e 6,14, para sementes não trincadas e trincadas, respectivamente. Os valores de $\mathrm{pH}$ das soluções de embebição não influenciaram no desenvolvimento inicial do maracujazeiro amarelo. As sementes não trincadas apresentaram os melhores resultados, não sendo aconselhável o trincamento das mesmas nos processos de germinação e desenvolvimento inicial do maracujazeiro amarelo.
\end{abstract}

Termos para indexação: Maracujá amarelo, semeadura, Passiflora edulis.

\section{ABSTRACT}

The passion fruit plant is among the main fruits cultivated in the country, being the sowing of seeds the predominant method in the production of seedlings. The aimed of this work was to evaluate the effect of the water $\mathrm{pH}$ of soaking and of the cracking of the seeds on the germination and initial development processes of the yellow passion fruit, cv. IAC 277. The work was carried out at the Department of Plant Science, of the Federal University of Viçosa (MG), Brazil. The treatments were constituted of cracking and no cracking seeds soaked for 24 hours into solution of distilled water at pHs 3.0; 4.0; 5.0; 6.0 and 7.0. After, at the greenhouse, the seeds were sowed in plastic boxes being used as fine substrate washed sand. The experiment was designed in a completely randomized blocks, in a factorial $5 \times 2$ ( $\mathrm{pH}$ of the solution $\mathrm{x}$ cracking of the seed), with four replications, where each plot constituted of 50 seeds. After 28 days of sowing, the following characteristics were evaluated: germination and survival percentages; emergence speed; total plantlet length; plantlet height; first root length and plantlet mass total drought. It was concluded that, $\mathrm{pH}$ values of the soaking solutions were favorable at the $\mathrm{pHs}$ of 3.81 and 6.14, for no cracking and cracking seeds, respectively. The $\mathrm{pH}$ values of the soaking solutions did not influence on the initial development of the yellow passion fruit. The no cracking seeds presented the best results, not being recommended the cracking of the seeds for the germination and initial development processes of the yellow passion fruit.

Index terms: Passion fruit, sowing, Passiflora edulis.

(Recebido em 21 de dezembro de 2005 e aprovado em 22 de dezembro de 2006)

\section{INTRODUÇÃO}

Das mais de 400 espécies de Passifloraceae, cerca de 50 a 60 produzem frutos comestíveis, dentre estas se destacam algumas nativas do Brasil (DONADIO et al., 2002). No País, as espécies nativas mais conhecidas e de maior aplicação comercial são o maracujá-amarelo (Passiflora edulis f. flavicarpa Degener) e o maracujároxo (P. edulis f. edulis Sims).

O maracujazeiro está entre as principais espécies frutíferas cultivadas no País, com produção de 3,4 bilhões de frutos, numa área de 38.522 ha, no qual o coloca na

'Doutor - Departamento de Fitotecnia/DFT - Universidade Federal de Viçosa/UFV - Campus Universitário, s/n - 36570-000 - Viçosa, MG americowagner@ibest.com.br, rsalexandre@cklick21.com.br - Bolsista CAPES

2Doutor - Universidade Federal do Acre/UFAC - Campus Universitário Reitor Aulio Gelio Alves de Souza - Rodovia BR 364, Km 04 - Cx. P. 500 - 69915-900 Rio Branco, AC - jacsonrn@gmail.com

${ }^{2}$ Mestrando - Departamento de Fitotecnia/DFT - Universidade Federal de Viçosa/UFV - Campus Universitário, s/n - 36570-000 - Viçosa, MG agropimentel@yahoo.com.br - Bolsista CNPq.

${ }^{3}$ Doutor - Departamento de Fitotecnia/DFT - Universidade Federal de Viçosa/UFV - Campus Universitário, s/n - 36570-000 - Viçosa, MG bruckner@ufv.br 
sexta posição, perdendo apenas em área produzida para citros (900.000 ha), caju (650.000 ha), banana (600.000 ha), manga (60.000 ha) e abacaxi (43.000 ha). A demanda desta fruteira ocorre, principalmente, no mercado interno, que absorve a maior parte da produção, caracterizando-se por ser uma cultura de pequenas áreas, o que representa uma alternativa aos pequenos produtores (CUNHA \& CARDOSO, 1999).

A propagação do maracujazeiro pode ser feita através de sementes, estacas e enxertia, porém o método predominante é a produção de mudas por meio de sementes. Contudo, o período de germinação de sementes de maracujazeiro é extremamente irregular, podendo oscilar entre 10 dias a três meses (LUNA, 1984).

Morley-Bunker (1974) descreve que algumas espécies de Passiflora possuem dormência em suas sementes ocasionada pelo mecanismo de controle da entrada de água para o seu interior, devido à dureza do tegumento, necessitando de tratamentos para sua superação. Os métodos de superação de dormência a serem empregados deverão promover aberturas nesta, permitindo a embebição, como ocorre com o uso de escarificações físicas e químicas.

A dormência das sementes é uma forma natural de distribuir a germinação no tempo e no espaço, além de permitir que a semente inicie a germinação quando as condições ambientais vierem a favorecer a sobrevivência das plântulas (PEREZ, 2004). Porém, a produção comercial é facilitada quando as práticas culturais podem ser aplicadas de forma contínua e uniforme. Para isso, há necessidade de uniformidade de desenvolvimento das plantas, o que se inicia na germinação das sementes e na emergência das plântulas (ZAIDAN \& BARBEDO, 2004).

$\mathrm{O}$ valor do $\mathrm{pH}$ é definido como a atividade do íon hidrogênio, expressa com logaritmo negativo da sua concentração, e determina a acidez relativa de um meio. Sabe-se que o pH do solo é de grande importância para o crescimento da planta, devido ao seu efeito na disponibilidade de nutrientes, em especial, de micronutrientes (HANDRECK \& BLACK, 1999).

Entretanto, a influência do pH sobre a germinação tem recebido pouca atenção. Valores de $\mathrm{pH}$ menores que 3,0 e superiores a 8,0 tem sido descritos como inibidores do processo germinativo (JANSEN \& CRONIN, 1953; MALHOTRA, 1930).

Ferreira (2004) recomenda o controle do $\mathrm{pH}$ e da concentração de extratos brutos durante os testes de germinação realizados em laboratório, pois pode haver neles a presença de substâncias como açúcares, aminoácidos e ácidos orgânicos, os quais influem na concentração iônica e são osmoticamente ativos.

Existem relatos dos efeitos da embebição das sementes de maracujazeiro em água (WAGNER JÚNIOR et al., 2003), água de coco (WAGNER JÚNIOR et al., 2006), água aquecida (MELETTI et al., 2002) e em ácido giberélico (GALDINO et al., 2003), porém, não foram encontrados informações a respeito do efeito $\mathrm{pH}$ da água de embebição sobre os processos de germinação do maracujazeiro amarelo.

Assim, o objetivo deste trabalho foi avaliar o efeito do $\mathrm{pH}$ da água de embebição e do trincamento das sementes nos processos de germinação e desenvolvimento inicial do maracujazeiro amarelo, cultivar IAC 277.

\section{MATERIAL E MÉTODOS}

O trabalho foi realizado no Setor de Fruticultura, do Departamento de Fitotecnia, da Universidade Federal de Viçosa (MG), de abril a maio de 2004. As sementes utilizadas foram extraídas de frutos maduros de maracujazeiro amarelo (P. edulis f. flavicarpa Deg.), cultivar IAC 277.

Para extração das sementes, os frutos foram seccionados pela metade. A retirada do arilo foi realizada manualmente, através de fricção em peneira de malha fina, acrescentando-se cal virgem. Após a remoção do arilo, as sementes foram lavadas em água corrente e dispostas em papel toalha, mantendo-as à sombra para secagem em condições naturais de ambiente.

Após estes procedimentos, as sementes foram embebidas, durante 24 horas, em água destilada com $\mathrm{pH}$ ajustados para 3,0;4,0;5,0;6,0 e 7,0, em recipientes plásticos, utilizando-se $\mathrm{HCl}$ ou $\mathrm{NaOH} 1 \mathrm{~N}$, com auxílio do pH-metro portátil Cristol Microph 2001.

Os tratamentos foram constituídos de sementes não trincadas embebidas em solução líquida com pH 3,0 (T1); sementes não trincadas embebidas em solução líquida com pH 4,0 (T2); sementes não trincadas embebidas em solução líquida com pH 5,0 (T3); sementes não trincadas embebidas em solução líquida com pH 6,0 (T4); sementes não trincadas embebidas em solução líquida com pH 7,0 (T5); sementes trincadas embebidas em solução líquida com pH 3,0 (T6); sementes trincadas embebidas em solução líquida com pH 4,0 (T7); sementes trincadas embebidas em solução líquida com pH 5,0 (T8); sementes trincadas embebidas em solução líquida com pH 6,0 (T9); sementes trincadas embebidas em solução líquida com pH 7,0 (T10).

Nos tratamentos T6, T7, T8, T9 e T10, as sementes foram trincadas na extremidade funicular com auxílio de uma pequena morsa, antes do processo de embebição. 
No interior da casa-de-vegetação, as sementes foram semeadas a uma profundidade de $0,5 \mathrm{~cm}$, com espaçamento de $2 \times 2 \mathrm{~cm}$, em caixas plásticas com $40 \times$ 27 x $10 \mathrm{~cm}$, utilizando-se como substrato areia fina lavada.

Foi utilizado o delineamento experimental em blocos casualizados, num fatorial 5 x 2 (pH da solução x trincamento da semente), com quatro repetições, considerando como unidade experimental, cada 50 sementes.

As avaliações foram realizadas 28 dias após a instalação do experimento. As variáveis analisadas foram: porcentagem de germinação e de sobrevivência (\%); índice de velocidade de emergência (IVE) (MAGUIRE, 1962); comprimento total das plântulas (cm); altura das plântulas $(\mathrm{cm})$; comprimento de raiz primária das plântulas $(\mathrm{cm})$ e massa da matéria seca total das plântulas (g).

Os dados foram submetidos à análise de variância e, para aqueles que mostraram-se significativos foi realizada a comparação de médias pelo teste de Tukey $(\mathrm{a}=0,05)$ para fator qualitativo, e análise de regressão para fator quantitativo, por meio do programa computacional SANEST. Os dados das porcentagens de germinação e sobrevivência foram transformados segundo arco seno $\sqrt{x / 100}$. Os demais dados não sofreram transformação.

O IVE foi estabelecido com o teste de emergência e suas avaliações realizadas diariamente a partir do surgimento das primeiras plântulas normais (décimo dia após a semeadura até o vigésimo oitavo dia). Para determinação do comprimento total, altura e comprimento da raiz primária das plântulas, as mesmas foram retiradas dos substratos, cuidadosamente lavadas em água e mensuradas com auxílio de uma régua graduada em centímetros. Posteriormente, para obtenção da massa da matéria seca total, todas as plântulas de cada parcela foram colocadas em envelopes de papel e transferidas para estufa com circulação de ar a $60^{\circ} \mathrm{C}$, permanecendo até atingirem peso constante, obtido em 72 horas.

Durante a execução do trabalho a temperatura média do ar no interior da casa-de-vegetação foi de $20,3^{\circ} \mathrm{C}$, sendo que as temperaturas médias mínimas e máximas foram de $16,8^{\circ} \mathrm{C}$ e $26,3^{\circ} \mathrm{C}$, respectivamente.

\section{RESULTADOS E DISCUSSÃO}

Observou-se que a emergência das plântulas teve início dez dias após a semeadura, adotando-se como referência para marcar o início visível deste processo o aparecimento dos cotilédones. Resultados semelhantes foram obtidos por Pruthi \& Lal (1954), que observaram o início da germinação de maracujá amarelo entre 12 a 15 dias após a semeadura.

Nas condições brasileiras a germinação do maracujazeiro ocorre entre 2 e 4 semanas após a semeadura, dependendo das condições climáticas, sendo que no verão o período de germinação é menor e no inverno maior (SÃO JOSÉ, 1991).

A interação $\mathrm{pH}$ de solução $\mathrm{x}$ tricamento da semente, mostrou-se significativo somente para a porcentagem de germinação (Figuras 1A e 1B).

Para Figura 1A (sementes não trincadas) e 1B (sementes trincadas), o coeficiente de determinação, $\mathrm{r}^{2}=$ 0,73 e 0,84 , respectivamente, indicam bom ajuste do modelo aos dados observados. Os pontos mínimo e máximo para as sementes não trincadas foram de 6,08 e 3,81, respectivamente. Já para as sementes trincadas, os pontos mínimo e máximo foram de 3,69 e 6,14, respectivamente.
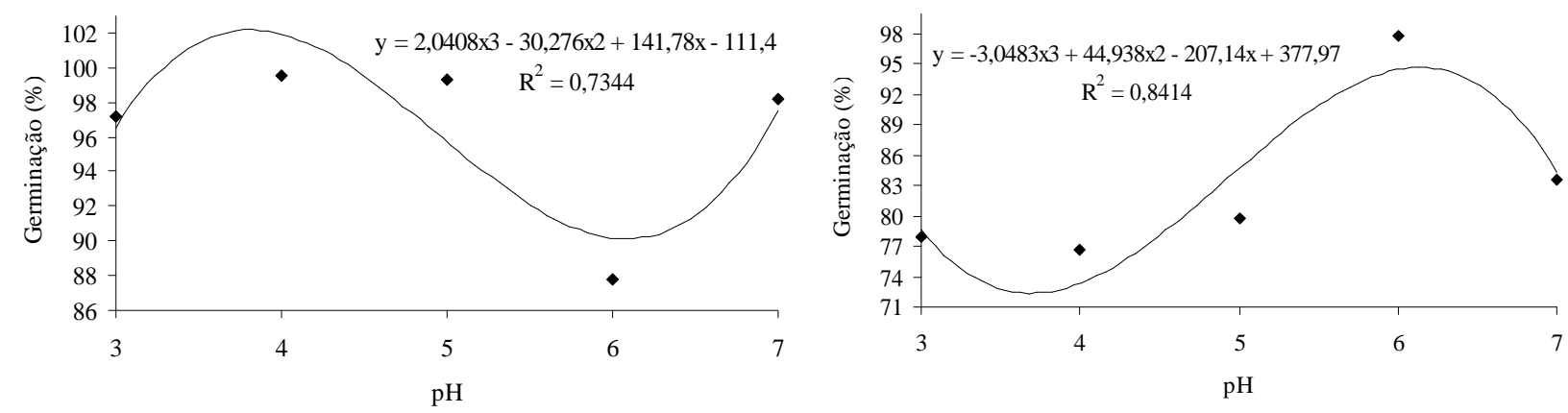

FIGURA 1 - Médias de germinação de sementes não trincadas (A) e trincadas (B) de maracujazeiro amarelo, embebidas em soluções de água destilada com diferentes valores de $\mathrm{pH}$. 
Com isso, observa-se que com o trincamento das sementes, a embebição das mesmas em água com valor de $\mathrm{pH}$ mais baixo, ou seja, mais ácido, prejudicou o processo germinativo. Resultados diferentes foram obtidos com a germinação de sementes não trincadas, o qual, mostrou-se favorável a embebição em água com pH mais ácido.

Todavia, quanto aos diferentes valores de $\mathrm{pHs}$ nas soluções de embebição, as análises de variância não foram significativas em todas as variáveis analisadas. Resultados semelhantes foram obtidos por Chan (1937) que descreveu que a germinação de muitas espécies não é afetada por valores de $\mathrm{pH}$ entre 3,0 e 7,0.

O processo de trincamento da semente apresentou diferenças significativas no comprimento total e de raiz primária das plântulas e massa da matéria seca total (Tabela 1).

De acordo com a Tabela 1, observa-se que as sementes de maracujazeiro amarelo não trincadas apresentaram os maiores valores no comprimento total e comprimento da raiz primária, além da massa da matéria seca total das plântulas.

Acredita-se que o processo de trincamento utilizado nas sementes pode ter danificado as sementes, interferindo negativamente nos resultados.

O porcentual germinativo é dependente de fatores internos e externos relativos às sementes, porém todo processo ocorrera normalmente se não houver nenhuma restrição durante os estágios de germinação, compreendidos pela embebição, atividade enzimática e respiratória, digestão, translocação, assimilação e crescimento. Durante o estágio de embebição, a água é fundamental para a reativação do sistema metabólico e a síntese de novos compostos no momento da germinação.
Neste sentido, a adoção de métodos de escarificação ou trincamento quando utilizada nas sementes com problemas de embebição pode favorecer a entrada de água pelas mesmas, possibilitando uma re-ativação mais rápida de seu sistema metabólico, conseqüentemente acelerando seu processo germinativo (WAGNER JÚNIOR et al., 2006).

Porém, de maneira geral, a análise dos resultados indica que as sementes de maracujazeiro amarelo estudadas não demonstraram problemas de dormência pelo mecanismo de controle da entrada de água para o seu interior, uma vez que, os melhores resultados foram obtidos com sementes não trincadas.

Resultados semelhantes foram obtidos por Ferreira (1998), que observou que as sementes de $P$. edulis Sims f. flavicarpa O. Deg., P. alata Dryand., $P$. giberti NE Brow e $P$. caerulea $\mathrm{L}$. não apresentam impedimentos à entrada de água no seu interior, embora o tempo de embebição seja diferente para cada uma das espécies.

Entretanto, Tsuboi \& Nakagawa (1992), utilizando lixa, ácido sulfúrico e água quente, demonstraram o efeito benéfico da escarificação sobre a taxa e a velocidade de germinação de sementes de maracujá-amarelo. Já Wagner Júnior et al. (2003) descreveram que a escarificação com lixa só teve efeito nas sementes embebidas com água de coco, não sendo observado o mesmo efeito nas sementes embebidas com água.

Contudo, deve-se considerar a dormência de sementes de Passifloráceas, uma vez, que autores, como Almeida et al. (1988) relataram ter encontrado baixa germinação em sementes de maracujazeiro amarelo consideradas fisiologicamente maduras, sugerindo a existência de outros fenômenos interferindo no processo.

TABELA 1 - Médias de sobrevivência (PS), comprimento total (CT), altura de plântula (AP), comprimento de raiz primária (CR), massa da matéria seca total das plântulas (MMST) e índice de velocidade de emergência, em sementes de maracujazeiro amarelo tricandas e não trincadas.

\begin{tabular}{clccccc}
\hline Semente & PS $(\%)$ & CT $(\mathbf{c m})$ & AP $(\mathbf{c m})$ & CR $(\mathbf{c m})$ & MMST $(\mathbf{g})$ & IVE \\
\hline Trincada & $99,08 \mathrm{~ns}$ & $9,82 \mathrm{~b}$ & $3,49 \mathrm{~ns}$ & $6,33 \mathrm{~b}$ & $1,02 \mathrm{~b}$ & $5,09 \mathrm{~ns}$ \\
Não Trincada & 99,90 & $10,72 \mathrm{a}$ & 3,47 & $7,24 \mathrm{a}$ & $1,19 \mathrm{a}$ & 5,38 \\
\hline CV $(\%)$ & 6,66 & 11,60 & 9,58 & 17,97 & 11,98 & 17,44 \\
\hline
\end{tabular}

*Letras diferentes na mesma coluna diferem significativamente ao nível de 5\% de probabilidade pelo teste de Tukey. ns - não-significativo ao teste F.

1. Comparação feita com transformação em arco seno $\sqrt{x / 100}$. 


\section{CONCLUSÕES}

Os valores de $\mathrm{pH}$ das soluções de embebição tiveram efeitos na germinação do maracujazeiro amarelo.

Os valores de $\mathrm{pH}$ das soluções de embebição não afetaram o desenvolvimento inicial do maracujazeiro amarelo.

As sementes não trincadas apresentaram as melhores taxas de germinação e desenvolvimento inicial do maracujazeiro amarelo.

\section{REFERÊNCIAS BIBLIOGRÁFICAS}

ALMEIDA, A. M.; NAKAGAWA, J.; ALMEIDA, R. M. de. Maturação de sementes de maracujá amarelo: experimento 1. In: CONGRESSO BRASILEIRO DE FRUTICULTURA, 9., 1987, Campinas. Anais... Campinas: SBF, 1988. p. 625-630.

CHAN, C. T. Study of the relation of different $\mathrm{pH}$ values of nutrient solution and tree seed germination. Journal Agricultural Assn, [S.1.], v. 158, p. 21-47, 1937.

CUNHA, M. A. P.; CARDOSO, C. E. L. Variabilidade genética e melhoramento do maracujá. In: QUEIROZ, M. A. de; GOEDERT, C. O.; RAMOS, S. R. R. (Orgs.). Recursos genéticos e melhoramento de plantas para o nordeste brasileiro. Versão 1.0. Petrolina: Embrapa Semi-Árido; Brasília, DF: Embrapa Recursos Genéticos e Biotecnologia, 1999. Disponível em: <http://www.cpatsa.embrapa.br.>. Acesso em: 13 nov. 2006.

DONADIO, L. C.; MÔRO, F. V.; SERVIDONE, A. A. Frutas brasileiras. Jaboticabal: UNESP, 2002. 288 p.

FERREIRA, A. G. Interferência: competição e alelopatia. In: FERREIRA, A. G.; BORGHETTI, F. Germinação: do básico ao aplicado. Porto Alegre: Artmed, 2004. p. 251-262.

FERREIRA, G. Estudo da embebição e do efeito de fitoreguladores na germinação de sementes de Passifloráceas. 1998. 146 f. Tese (Doutorado em Horticultura) - Faculdade de Ciências Agronômicas, Universidade Estadual Paulista, Botucatu, 1998.

GALDINO, L. C. G.; FUMIS, T. F.; SAMPAIO, A. C.; OLIVEIRA, O. M. Germinação de sementes de maracujá amarelo híbrido 'IAC-277' submetidas a diferentes concentrações de ácido giberélico. In: SIMPÓSIO BRASILEIRO SOBRE A CULTURA DO MARACUJAZEIRO, 6., 2003, Campos dos Goytacazes. Anais... Campos dos Goytacazes: [s.n.], 2003. CD-ROM.
HANDRECK, K.; BLACK, N. Growing media for ornamental plants and turf. Sydney: University of New South Wales, 1999. 448 p.

JANSEN, L. L.; CRONIN, E. H. Halogeton on trial. Farm \& Home Science, [S.1.], v. 14, p. 38-39, 1953.

LUNA, J. V. U. Instruções para a cultura do maracujá. Salvador: EBAPA, 1984. 25 p. (Circular técnica, 7).

MAGUIRE, J. D. Speed of germination aid in selection and evaluation for emergence and vigour. Crop Science, Madison, v. 2, n. 2, p. 176-177, 1962.

MALHOTRA, R. C. A new method of germination and the influence of hydrogen-ion concentration on the germination and growth of Helianthus annuus and Lycopersicum (sic) esculentum. Journal Indian Botanical Society, New Delhi, v. 9, p. 218-239, 1930.

MELETTI, L. M. M.; FURLANI, P. R.; ÁLVARES, V.; SOARES-SCOTT, M. D.; BERNACCI, L. C.; AZEVEDO FILHO, J. A. Novas tecnologias melhoram a produção de mudas de maracujá. O Agronômico, Campinas, v. 54, n. 1, p. 30-32, 2002.

MORLEY-BUNKER, M. J. S. Some aspects of seed dormancy with reference to Passiflora spp. and other tropical and subtropical crops. London: University of London, 1974. 43 p.

PEREZ, S. C. J. G. A. Envoltórios. In: FERREIRA, A. G.; BORGHETTI, F. Germinação: do básico ao aplicado. Porto Alegre: Artmed, 2004. p. 125-134.

PRUTHI, J. S.; LAL, G. Germination trials in passion fruit seeds. Indian Journal of Horticulturae, Bangalore, v. 11, n. 4, p. 138-144, 1954.

SÃO JOSÉ, A. R. Propagação do maracujazeiro. In: SÃO JOSÉ, A. R.; FERREIRA, F. R.; VAZ, R. L. A cultura do maracujá no Brasil. São Paulo: UNESP, 1991. p. 25-41.

TSUBOI, H.; NAKAGAWA, J. Efeito da escarificação por lixa, ácido sulfúrico e água quente na germinação de sementes de maracujá-amarelo (Passiflora edulis $\mathrm{f}$. flavicarpa Deg.). Científica, Jaboticabal, v. 20, n. 1, p. 6372, 1992. 
WAGNER JÚNIOR, A.; ALEXANDRE, R. S.; NEGREIROS, J. R. S.; PARIZZOTTO, A.; BRUCKNER, C. H. Influência da escarificação e do tempo de embebição das sementes sobre a germinação de maracujazeiro (Passiflora edulis f. flavicarpa Degener). Revista Ceres, Viçosa, v. 52, n. 301, p. 369-378, 2006.

WAGNER JÚNIOR, A.; NEGREIROS, J. R. S.; ALEXANDRE, R. S.; PARIZZOTTO, A.; BRUCKNER, C.

H. Influência da escarificação, da água e da água de coco na germinação de sementes de maracujazeiro (Passiflora edulis f. flavicarpa Degener). In: SIMPÓSIO BRASILEIRO SOBRE A CULTURA DO MARACUJAZEIRO, 6., 2003, Campos dos Goytacazes. Anais... Campos dos Goytacazes: [s.n.], 2003. CD-ROM.

ZAIDAN, L. B. P.; BARBEDO, C. J. Quebra de dormência em sementes. In: FERREIRA, A. G.; BORGHETTI, F. Germinação: do básico ao aplicado. Porto Alegre: Artmed, 2004. p. 135-146. 